\title{
In Perfect Shape Media Representations of Women's Health in Brazil
}

\section{Everardo Rocha}

\author{
PhD in Social Anthropology, National Museum/ UFRJ \\ Associate Professor of the Department of Social Communication at Pontifical Catholic \\ University of Rio de Janeiro - PUC-Rio. \\ Marina Frid \\ Master in Social Communication, \\ Pontifical Catholic University of Rio de Janeiro - PUC-Rio. \\ E-mail: marina_frid@yahoo.com.br
}

\section{Doi:10.5901/mjss.2013.v4n9p474}

\begin{abstract}
This paper suggests an investigation of media representations of women's health, fitness and wellbeing in Brazil. In this work, we will approach the issues of modern consumption, communication and social identities from an anthropological perspective with the purpose to discuss the role of the media in creating a health ideal characteristic of contemporary culture. A perfect, athletic and desirable body seems to be among the main ideological concerns and daily practices of Brazilian society. In this sense, we observe how media representations suggest the woman's body to be treated, piece by piece, so that she may conquer a perfect shape. In order to demonstrate this ideal of women's health as elaborated by mass media, we will analyze selected reports and ads published during a year in Brazilian magazines that target female readers. This may be an interesting path to observe the construction of a feminine model and wellbeing experience that is distinctive of our time. Finally, this study hopes to contribute to the understanding of how media images of health may impact everyday practices of contemporary culture in Brazil.
\end{abstract}

Keywords: communication and consumption; gender and media; women's health; media and wellbeing.

\section{Culture, consumption and communication}

This paper aims to analyze certain representations of Brazilian women's health, fitness and wellbeing elaborated in media narratives, as part of the debate regarding the connection of certain meanings that support the imaginary and consumption practices experimented in contemporary culture. The means to acquire and maintain an attractive appearance, as well as a healthy and productive life, are an ever greater issue for society, occupying a central place among the images and representations produced by the media. Our social experience seems imbued with media narratives that involve everyone in a permanent process for preserving health and youth. This broad and persistent speech is translated into activities common to urban spaces, such as gym centers, spas, cosmetic surgeries, exams, exercises, diets, and so on.

In fact, a perfect, athletic, desirable and forever young body is among the main ideological concerns and everyday practices of our present society. In order to study this phenomenon and, above all, its media representations, the anthropological perspective may contribute to the analysis of certain ideals that cross our society since modernity. Therefore, guided by theories of culture, consumption and social identity, this work proposes an investigation of messages disseminated by the media in search to demonstrate how this powerful "voice" (re)produces an ideal of health, good shape and wellbeing that all of us, one way another, more or less consciously, seem to pursuit. This ideal is formed by representations that are linked to products and services, constructing a particular market of consumer goods for health, fitness and wellbeing.

The intention here is to approach health as an important part of media narratives and of the issue of consumption, observing the construction of a feminine model and wellbeing experience as elaborated by mass culture. Therefore, we propose here an overview of ideas presently circulating about women's health, based on an analysis of press materials where the concept may appear explicitly or implicitly. The media used for gathering evidence were Brazilian magazines 
that target specifically female readers. The three publications "Claudia", "Nova" and "Boa Forma" (or "Good Shape" in English) were collected during a period of twelve months, between June 2011 and May 2012. The choice of these magazines is due, especially, to their broad circulation, since they are among the biggest editorial productions aimed towards women in Brazil. It is also worth mentioning that each one of them has different content proposals, being "Claudia" and "Nova" about more general subjects and "Boa Forma" dedicated specially to body and health care.

To begin this research, it is interesting to review some key ideas about consumption studies, communication and cultural identities in modern-contemporary society. Culture can be seen as a result of the relations that human beings of a given group establish with nature. According to Sahlins (1976), the cultural object gains its existence in a symbolic and historic system once permeated with meanings that are created and attributed by humans. So, because of this process of designating sense, and as a result of a productive act, a "thing" goes from being a simple matter to become an "artifact", a "good", something that integrates and characterizes a culture. As the author explains, a "canoe" is a "canoe" because every stroke in the wood, from the very first, is imbued with meaning. Wood is not "merely" chopped, because behind this act there is always a meaningful purpose:

The problem is that men never merely "chop wood" as such. They cut logs for canoes, carve the figures of gods on war clubs, or even chop firewood, but they always enter into relations with wood in a specific way, a cultural way, in terms of a meaningful project whose finality governs the terms of the reciprocal interaction between man and tree. (...) The response to the last stroke depends on an objective that is not given to the process as a natural process; that stroke and every one before it back to the initial cut depend on the meaningful intent. The determinate interaction of tree-eyesbrain-etc. has been stipulated by a symbolic order; it is a paradigmatic example of nature harnessed to the service of culture. (Sahlins, 1976, p.91)

Correspondingly, individuals do not navigate canoes, or sit at tables to have their meals, or play a violin without having a background - of customs, skills, knowledge - that allows them to choose a means of transportation, to adopt etiquette rules and establish a musical taste. "Culture is public because meaning is." (Geertz, 1978, p.12): a collective, and not individual, property that enables the structuring of symbolic exchanges. According to this idea that acts are instilled with sense and thus are transformed into signs, we may expand the discussion concerning the transition of matter to artifact, of thing to consumer good. In their work, Douglas and Isherwood (1979) approach the question of the uses of goods from an anthropological perspective. The authors suggest that the economic view on the subject poses a problem precisely because it places consumption as a private issue. However, as previously explained, if a good only "exists" when permeated with meaning - a collective quality that enables symbolic exchanges - it is possible to understand consumption as something not of the individual plan, but as a shared property instead.

Hence, if meanings are attributed to "things" that through this process become cultural objects, the relationships we establish with those "things" - as needs, utilities and desires - are proper of our culture. Like Douglas and Isherwood (1979) pointed out, goods are neutral: they may serve as walls or as bridges depending only on their social uses. That is why studying consumption becomes such an important part of researches concerning our modern-contemporary culture, even though approaching this theme is still a great challenge. As a phenomenon that emerges in modernity, consumption is placed in the center of everyday debates, but many times as a kind of villain, responsible for financial crisis, environmental degradation, poor health, and so on, that society must suppress. Alternatively, the anthropology of consumption suggests its systematic study as a cultural phenomenon, far from an approach that restricts it to utilitarian, moralistic or hedonistic perspectives (Rocha, 2004).

Thus, if investigating consumption is fundamental to understand our contemporary culture, accordingly, the study of media narratives encompassing the phenomenon deserves also a great deal of attention in this research project. Agreeing with Geertz (1978), human beings are suspended in webs of meanings that we ourselves created. In this sense, the media may be observed as an integral part of our impressive symbolic system, offering a vast repertoire of meanings that circulate indistinctly among different social levels. According to Rocha (2002), media narratives are articulated to the ideological structure of society and confer sense to our world while reproducing everyday events in newspapers, movie pictures, soap operas, advertisements, websites, and so on. The significance of mass communication is due to its inscription in the social order, operating like a mirror that reveals and projects cultural values, life styles, emotions, heroes, rituals, myths, representations and so forth.

If the cultural object results from the attribution of sense, the media and, particularly, advertising, is the instrument responsible for dressing up production and later disseminating its meanings. In the cycle that includes production, communication and consumption, advertising occupies a privileged space, since its reason par excellence is to position products and services in the market. The industrial production, sequenced and indistinguishable, needs to be covered 
with meanings in order to acquire a place in the field of consumption (Rocha, 2006). However, this process is not exclusive to advertising messages and can also be observed in other media narratives. After all, consumption is something absolutely important to sustain the many communications systems.

\section{Ideology, identity and social representation}

In the last decades, the Social Sciences have focused their attention on a variety of fairly recent events in order to study society and the modern-contemporary individual. In retrospect, since the eighteenth century we have crossed a series of revolutions - social, scientific and technological - and experienced a sequence of ideologies - illuminist, capitalist, socialist, feminist, and so on - that acquired historical relevance. Furthermore, a phenomenon that gained strength in the 1990s, known as globalization, added to the challenges of analyzing a world that had recently been "unified": in 1989, capitalism finally seemed to triumph, as images of the fall of the Berlin wall were broadcasted throughout the globe. The neoliberal logic of "every man for himself" was then assured, nurturing the idea that human beings are autonomous individuals and able to succeed by their own means.

The triplet combining capitalism, communication and globalization is a fertile ground for reflections of a world that became curiously more complex, raising different interpretations on the issues concerning identities and behaviors. While scholars, such as Lipovetsky (2007), emphasize the axis of individualism to understand the present time consumers, others like Hall (1992) focus on the impact of the globalizing phenomenon over cultural identities. The authors suggest, respectively, the concepts of the "hyper-consumer" and the dislocation of social identities as the result of a new era. Certainly, there is space for different approaches, but the purpose here is to develop a reflection from an anthropological perspective. More specifically, the intention is to follow the path of research that Douglas and Isherwood (1979) suggested as the Anthropology of Consumption.

To approach the matter of social identity, Rocha (2006) indicates a view that understands the concept as something placed in the intersection between the principles of classification and value. Classification indicates a specific position in a given structure, while value is the meaning that covers that position. Thus, the author suggests social identities may be placed at the very intersection of the line traced by the axis of classification and the line traced by the axis of value. As mentioned above, products and services obtain meanings from advertising (besides other mechanisms of design and marketing), which are later vastly transmitted by different media. This process converts the world of production into the world of consumption, transforming lifeless matter into goods, "things" into "needs", "utilities", and "desires". In other words, consumer goods accomplish their classificatory vocation once imbued with meanings by media narratives. This classification system, where "goods" and "people", reciprocally, establish meaning, is the key behind consumer practices. In this sense, consumption is the arena for social classifications of the modern-contemporary world (Rocha, 2002).

The phenomenon of consumption is stage for our representations in everyday life. According to the sociological analysis proposed by Goffman (1959), inspired in dramaturgical principles, every individual performs different roles in his or her daily routine. The woman, for instance, can appear as a professional, a spouse, a mother, a lover, a housewife, and so on, according to circumstances and the "audience" to which she presents herself. The author suggests that when we are going to meet someone, we usually look for information about this person in hopes to form a first opinion and prepare ourselves for this interaction. If there is no time or conditions for a previous investigation, we may observe other things, such as the very setting (an office), the occasion (a business meeting), and other people involved (work colleagues) that allow us to make inferences about this new acquaintance. If, on the one hand, we make an impression of someone after a first engagement, on the other, we also have to do our best to express our "self" in order to properly impress the "other" person.

In this sense, the products and services we choose give clues to who we are and what role we are representing in every interaction and every social "scene". Fashion offers good examples, since it serves to characterize the parts we are playing in different circumstances. When meeting someone at the gym, for example, we expect him or her to be dressed in sports outfits. But, if this person is wearing jeans or a suit, this may cause some awkwardness during the interaction. A man can be recognized as a physician for certain aspects, like the white jacket, the stethoscope around the neck, the diploma hanging on a wall, the gurney to examine the patient, and so forth. But even before a consultation, it is possible to form an opinion of him by gathering information like: the school where he graduated; the address of his office; the hospitals he works in; the patients he assists; the fees for his services; and even the availability of his agenda. The media elaborates our collective imaginary, offering elements for us to classify the world that surrounds us, but also, it inspires our everyday performances and acting, in a Goffman theatrical sense. 
Continuing with Goffman, eventually, certain unintentional gestures or accidental events may occur, which compromise the representation and disturb the audience's attention. In its health section, "Nova" magazine (year 40, n4) remembers some of these embarrassing situations and offers some tips for readers to deal with certain "biological" slips: "down with embarrassment! Do not let your body make a fool of yourself right when you need to show you are amazing" 1. So, learn how to control your need to use the toilet when you feel your intestine "didn't enjoy that much the spicy Thai food". Certainly, "spending a long time in his bathroom is out of the question". And what if you suddenly "start to have a sneezing crisis" when you are out at night? "Dip your nose in a glass of water". Since "there is no Louboutin that can save you from smelly feet", wash them with "a glass of vodka" to amend the situation "when you are out with a cute guy and feel you two may stretch the night".

Lipovetsky (2007) associates consumer practices to an extreme individualism of contemporary society. Today, "hyper-consumers" would no longer expect to classify themselves in relation to others through consumption, but wish to feel emotions, live experiences, improve quality of life, conserve youth and preserve health. Therefore, it seems important to dedicate some time for a brief analysis of individualism as a concept. Dumont (1986) placed modern ideology under perspective for a careful reflection over the notion we possess of individualism. The author establishes a clear and important distinction between the holistic and the individualist societies: "Where the individual is a paramount value I speak of individualism. In the opposite case, where the paramount value lies in society as a whole, I speak of holism." (Dumont, 1986, p.25). Among his studies over the theme and his historical elaboration, it is interesting to mention the author's analysis of the religious sphere, where he refers to the Christendom of the Middle Ages and the vision of man as an "individual-in-relation-to-God". Dumont indicates how in this principle the individual's value had already been recognized, but as a creature that resides in the world (human) subordinated to an "outworldly" entity (God). In order to illustrate this idea, the author imagines a picture of two concentric circles. The larger represents individualism in relation to God that encompasses the smaller one, which symbolizes the acceptance to the needs, duties and commitments of holistic social life. Thus, the tension between the "individual" and the "universal" established at the center of Christian thinking becomes clear: individuals receive their value from God to whom they must serve. However, this dualism progressively lost space in modernity, weakening holism as an ideological category. Consequently, the "individual-in-relation-to-God" gave place to the notion of the "modern individual".

Societies known to be holistic are hierarchically organized, that is, as Dumont (1986) explains, when the paramount value encompasses the opposing value. For example, in societies that privilege machismo, the female value is subordinated to the male value. In his reflection over the sexual moral, Guillebaud (1999) analyzed a moment of "revolution" that had its peak between the decades of the 1960s and the 1970s. The ultimate goal back then was precisely to invert the logic of values that ruled sex in society. Consequently, the feminist cause gained strength and the ideal of equality between women and men in society seemed closer than ever: the encompassed value was battling for its autonomy. However, the author follows with an investigation that reveals how the accomplishments of the so-called sexual revolution were actually much more difficult to maintain than anticipated at that point. In the issue of sex, the "ghost" of AIDS during the 1980s threatened the primacy of individualism and sexual liberty. Suddenly, the permissive atmosphere gave place to a more preventive attitude. Gender prejudices flourished and fear began to retract men and women that not so long before were intense and confident. There it was the challenge to conciliate the new Western moral with social hygienic concerns (Guillebaud, 1999).

According to Dumont (1986), hierarchies persist in modernity, but there are instruments that neutralize or substitute these relationships, because modern ideology is hostile to this form of social structure. The author suggests that some of the main illuminist thinkers recognized the difficulty to conciliate individualism with authority, equality and differences of power inherent to Western society and the State. The paradox of modernity had already been indicated by Rousseau: humans are free individuals without ceasing to be social beings (Dumont, 1986). In this sense, the question of individualism becomes far more complex than to think of modern-contemporary individuals as people that make selfcentered choices in search for personal satisfaction. Although "individualists", that is, (ideally) autonomous human beings, standing in equal positions, women and men in society need to share experiences and occupy their designated spaces, establishing themselves in a relational world, even as individuals.

\section{The woman and health in the media}

A woman wearing a bikini, tanned skin, lying down with her hat beside her, as if she were enjoying her time at the beach.

${ }^{1}$ All texts quoted from the examined magazines were freely translated from Portuguese to English by the authors. 
The photo and the title of the text suggest: "Throw yourself"! And making a correspondence to different parts of her body, "Nova" (year 40, n²) reveals the "ten best health pieces of advice that you have always wanted to hear". For legs, "get up on your high heel", because it may be good for you "if it is about 4 centimeters long". For thighs the hint is "savor chocolate: a small bar has only 170 calories and antioxidant substances". Pointing to the region of the groin, the reader is given "one more reason to reach climax: orgasms reduce stress and may enhance your creativity at work. Really"! But that is not just because sex is pleasurable. At this moment, "the body releases endorphins and oxytocin, hormones that increase your sense of wellbeing". For the uterus, drink coffee, because scientists "discovered that women who drink four to seven cups of coffee a day have $25 \%$ less chances of having cervical cancer". If you are "dying for those expensive sun glasses, you have now a good reason to "fetch your credit card and run to the store", because this "accessory (with UV filter) is indispensable for the health of your eyes". In the ears, "load your iPod", since "music may help your brain to fight against aging". For the brain, "negotiate deadlines and make some time to relax: it might be nice to catch a movie after a long day". After all, "working extra hours and having a job where pressure is huge can attack your mental health".

This is how many of the news, stories, articles and sections dedicated to women's health follow in Brazilian publications. Generally inspired by recent scientific findings and the clinical speech of specialists, the texts authorize and prohibit behaviors, give alerts and recommendations, clear doubts and introduce discoveries. Two of the magazines used as research material, "Claudia" and "Nova", are not dedicated exclusively to the topic of women's body and health care. The first proposes to be "complete, as a woman should be", offering the reader "inspiration, reflections and solutions"; the second, "stimulates boldness and courage to face challenges, the pursuit for pleasure without guilt and the construction of self-esteem and self-confidence". Both are very successful and established magazines in the editorial market. But, as going through their pages, it is surprising to notice how the concept of health is frequently explored, appearing as the central theme, related to a variety of issues, or even implied in other subjects. The unaware reader does not imagine that, as skimming a single issue of the magazine for information or entertainment, she or he may be exposed to so many representations, ideologies and images of healthy living. This is especially intriguing if we think about the recurrent presence of the theme in these publications as an indication of how health is becoming a primary and omnipresent concern for individuals in almost any age (Lipovetsky, 2007).

In fact, concerns suggested by the media with regards to health are innumerous and diverse. It is not just a classic question of physical and mental health, but a need for a constant state of vigilance with our body and our attitudes in each moment and aspect of our everyday life. For example, "science shows and Nova alerts: ovulation and shopping mall are as good a combination to empty your pockets as are $70 \%$ discount sales" (Nova, year $40, n^{0} 2$ ). There is a new explanation for women's "addiction" to shopping: "it's not just madness. It's biological". Hence, if during your ovulating period "you see something you like in a store, do not buy it. Go home, think it over and come back the next day. If you still wish to have it, then take it home".

However, certainly the most evident concern is related to weight-loss. There are countless tricks, diets and recommendations to "flatten" the tummy, "shrink" the waist, "burn" fat, "lose" some kilos and "shape" the woman's body. To be slim is not just a matter of aesthetics, as indicated by "Claudia" (year 51, $n^{0} 2$ ), "it is a health target!". The covers of "Boa Forma" explicitly represent this beauty ideal, now a matter of health as well, that is weight-loss. This notion that women are in constant need to drop a few kilos is confirmed through the many targets, diets and deadlines suggested every month as the path towards the great triumph. For example, the magazine proposes to "lose $6 \mathrm{~kg}$ in 1 month with the 3 herbs tea" in June 2011, to "speed up your metabolism and lose 4kg in 17 days" in September 2011, to "lose $3 \mathrm{~kg}$ in 15 days with the miraculous spaghetti" in March 2012, and like this, repeatedly, in every edition, covering an entire year of imperious diets, regimes and body improvements.

Sometimes, the challenge to conquer a slim body is "self-sabotage". Also, difficulties in losing weight may be a symptom of other health problems that need to be treated or the consequence of risky habits. As "Boa Forma" (year 27, no1) explains, there are at least "8 health problems that make you fat", even when you are dedicated to your diets and workouts. For example, "inflamed cells" form the white fat that accumulates in the belly, butt and thighs; "out of control emotions" are an issue, because "when you feel that knot on your throat, nothing works better to ease the agony than eating something"; thyroid illnesses such as hyperthyroidism can make women "gain, on average, from 3 to 5 kilos a year"; "too much stress" knocks down your metabolism; the "wrong contraceptive pill" can make you retain liquids; and "food allergies" can make you gain weight, as well as "instable hormones" caused by polycystic ovaries or bad sleeping. Furthermore: "working late hours can get you fatter", because "the organism of the person who sacrifices her sleep and works until late hours loses its capacity to recognize signs of hunger and satisfaction".

In 2011, the journalist Renata Ceribelli faced the challenge of losing weight on a nationally broadcasted television program. Her triumph was confirmed in August when she appeared as the cover star of "Claudia". Besides losing 9.5kg 
and reducing her waist measure in $14 \mathrm{~cm}$, Renata "improved her health, boosted her self-esteem and inspired thousands of Brazilians to take better care of themselves". The actress Fernanda Souza overcame a disease: "I won the fight against hyperthyroidism and dropped 4kg". Hence, top models, actresses and celebrities are frequently asked to reveal their secrets for maintaining a perfect body even "at the age of 50", as a "mother of two kids", or "after giving birth to twins". Perhaps, a "diet-therapy" adjusted to your personality can help: "are you most likely to be compulsive, impulsive, emotional or anxious?" (Nova, year 40, n ${ }^{\circ 4}$ ).

Furthermore, certain foods appear as heroes that help to cure and, most importantly, to prevent many unwanted conditions. A healthy eating habit can be "the definitive path for the end of cellulites, a negative belly, toned muscles, a dream hair and hydrated skin" (Nova, year 40, n²). Therefore, "for slimming", use coconut oil; "for baby skin", eat cashew; "an amazing hair", yellow sweet pepper; "to sleep well", cherry; "for rejuvenating", kiwi, and "to exterminate cellulites", red grapes. In December 2011, "Claudia" elected the "top 25 foods" of the year, which have incredible and medicinal powers. Dark chocolate has the anti-inflammatory effect of cocoa and may be good for the heart. Chia seeds "act against constipation, increase immunity, prevent osteoporosis, reduce triglycerides levels and help weight-loss". The cashew nut "reloads your levels of selenium, an important mineral for a long and healthy life, besides postponing aging and protecting your brain from neurodegenerative diseases". And sesame can be "pretty energetic" and help you "boost your sexual appetite".

Eventually, there is a certain change of speech, suggesting a more permissive attitude, contrary to all other rules dictated throughout the rest of the magazine. The "recipe for a perfect body" does not demand that you to give up certain pleasures. You just need to "wear the exact bras, watch your attitude when posing for a picture and follow other tips that release you from diets" (Nova, year 40, n4). To satisfy the activity of your hormones, "devour a nice piece of cake". Also, "drink regular refreshments", "prepare your own French fries" and "forget about calories". Remember to "buy clothes for yourself and not for the person you would like to be". Large breasts make your waist look thinner, so "go purchase new (and perfect) bras". And "have more (and exciting) sex". To increase your desire, ride a bike for 20 minutes, because this "improves your blood flow, which is essential for your sexual function".

In fact, sex becomes, above all, a fundamental element, or a very valuable currency, for physical and mental health, occupying a significant amount of pages in women's magazines. However, besides being considered a healthy practice, to have a quality "sex life", women should follow a series of recommendations, like diets, physical activities and schedules. Publications elaborate guides for women to learn how to handle their partners and guarantee "even hotter and better nights of pleasure" (Nova, year 40, no5). Having sex in the mornings is recommended, because "the levels of testosterone, the male sexual hormone, are higher" at this hour. "Invest in the power of cabbage palm", because this fruit has a substance that "expands blood vessels" called anthocyanin. Women should be patient before a second round, since men need to have a "phase of recovery" - jumping this stage "is not good for the quality of sex". Another recommendation is to hold back on alcohol. And also, "have sex with an empty stomach", or at least try avoiding fatty meals, for their inflammatory substances are carried to blood vessels.

For women to improve their sexual performance, "Claudia" suggests a kind of "intimate workout". Based on exercises that were first elaborated to treat patients with urinary incontinence, today, the gynecological physical therapy is recommended for "after giving birth, against difficulties, or just to spice things up" (Claudia, year 51, n4). Finally, taking into consideration so much advice is important, since, as already mentioned, sex is good for your health. It is a utopia of a perfect sexual health that everyone may aspire to accomplish. According to Guillebaud (1999), this perception of sexuality as an almost-problem of public health is making our representations of pleasure slip from freedom to obligation, from permission to injunction.

Another body part that gains increasing attention from the media is the brain, as a report in "Claudia" (year $51, n^{0} 4$ ) shows. Neuroscience already "indicates what to do in order to keep healthy the noblest organ of the human body". Although certain problems are communly associated to aging, "a healthy person does not lose its memory, clarity and reasoning just for reaching a certain age". However, some suggestions should be followed in order to age with a healthy brain, like doing "mental workouts" - reading, playing games and learning new skills - instead of watching television all day. The female gift of multitasking is inadvisable - a healthy attitude is "doing one thing at a time". The practice of regular aerobic activity "stimulates the forming of nervous cells and liberates protective substances for neurons", helping "the association of ideas, learning and memory retention", besides combating anxiety and depression. Certain "villains" should be controlled, such as chronic stress, cigarettes, alcohol, high cholesterol, hypertension and diabetes.

Along with healthy eating habits, sex and physical activities, there are alternative options. So, "take a deep breath". This "could be the key for a healthier, and happier, life" (Claudia, year 50, n012). The text explains that "in conventional medicine, researches show the connection between breathing physiology, neurology and behavior". Activities such as 
yoga may be "a powerful supporting treatment for problems like stress, depression and even panic syndrome, which today affects $3.5 \%$ of the world population - especially women". Furthermore, a wide variety of products arrives in the market with the promise to help consumers in their pursuit for prevention, relief and cure. To quote only a few advertising slogans: "conquer a prettier and healthier body with Mundo Verde products"; "Clear: a healthy hair scalp, for a beautiful hair from root to ends"; "Ensure: the complete and balanced nutrition for the new generation"; "Nivea Q10 Eyes Roll-on: experience and discover how it feels to have visibly younger and healthier skin".

The texts used throughout the analysis above offered some clues to begin a reflection on the conspicuous presence of the thematic of health and wellbeing in the media. It is only a beginning, since there is a huge availability of material for investigation and, certainly, much can be added to what was just exposed. Besides the outstanding issues of weight-loss, eating habits and sex, there are also endless narratives about "fights" against diseases, discoveries of medicine, and, above all, various hints to guarantee a long, healthy and youthful life. The incorporation of scientific discourse by mass communication generates a group of representations that, as observed in the case of magazines, has the main purpose to discipline the body and to engender a system of massive consumption of medical products and services for health and fitness. In this respect, Banet-Weiser and Portwood-Stacer (2006) indicate the construction of a post-feminist consumer that embarks in a project of self-actualization through cosmetic surgeries and diverse beauty treatments, emphasizing ideas of personal choice and individualization, instead of original feminist causes of social change and liberation.

As skimming magazines, the reader is offered an array of products and services for wellbeing, prevention and youth that is presented in advertisements as in journalistic reports. Every piece of the female body represented in the media has to be treated, one by one, with the appropriate beverages, foods, nutritional supplements, cosmetics, remedies, exams, therapies and so forth. As Rocha (2006) observes, the feminine individuality is mainly translated in advertising narratives as the property of a body and its parts. In this sense, the body is a woman's most important good that should be protected, enhanced and adorned in each and every one of its pieces. Thus, media delegates women's health to products and services that may satisfy their needs and aspirations. The absolute wellbeing can only be accomplished through consuming specific treatments for every single one of the female body fragments.

Finally, this study looked to identify significant traces for composing the contemporary ideal of Brazilian women's health, fitness and wellbeing. The analysis of the selected material revealed how media narratives systematically propose certain themes for women to consider, such as: the concern with weight, aging and beauty as a path for being complete and happy; the association of medical standards with particular ideologies and aesthetic preferences; the identification of "villains" like fat, cholesterol, stress, alcohol, sodas, cigarettes, etc., that act against "quality of life", "longevity" and "happiness"; the assimilation of discourses of specialists, celebrities and "ordinary" individuals; and, at last, the very plastic articulation of the ideas of wellbeing and health with the woman's different representations - sexy, professional, independent, partner, mother, wife, and so on. All of this forms an extensive inventory of rules for behaviors and consumptions with the purpose to gain fitness, health and wellbeing, which guides choices and practices of this female model reproduced in magazines. In this sense, representations of a woman's perfect shape - sustained through the acquisition and possession of several types of goods - may indicate an important perspective for communication studies and, specially, for researches about the surprising ways through which consumption is experimented in contemporary culture.

\section{Acknowledgment}

This paper results from researches supported by PECC - Research Program in Communication and Consumption Infoglobo Academy/PUC-Rio.

\section{References}

Banet-Weiser S. \& Portwood-Stacer L. (2006). I just want to be me again! Beauty pageants, reality television and post-feminism. Feminist Theory, vol.7(2), 255-272.

Douglas, M. \& Isherwood, B. (1979). The world of goods: towards an anthropology of consumption. London: Allen Lane.

Dumont, L. (1986). Essays on individualism: modern ideology in anthropological perspective. Chicago and London: The University of Chicago Press.

Geertz, C. (1978). The interpretation of cultures. New York: Basic Books.

Goffman, E. (1959). The presentation of self in everyday life. New York: Anchor.

Guillebaud, J.C. (1999). A tirania do prazer. Translated from French to Portuguese by Maria Helena Kühner. Rio de Janeiro: Bertrand 
Brasil.

Hall, S. (1992). "The question of cultural identity". In: Hall, S., Held, D. \& McGrew, T. Modernity and its futures. Cambridge: Polity Press. Lipovetsky, G. (2007). A felicidade paradoxal: ensaio sobre a sociedade do hiperconsumo. Translated from French to Portuguese by Maria Lucia Machado. São Paulo: Companhia das Letras.

Rocha, E. (2002). A sociedade do sonho: comunicação, cultura e consumo. 4th ed. Rio de Janeiro: Mauad.

Rocha, E. (2004). Apresentação. In: Douglas, M. \& Isherwood, B. O mundo dos bens: para uma antropologia do consumo. Translated from English to Portuguese by Plínio Dentzien. Rio de Janeiro: Editora UFRJ.

Rocha, E. (2006). A mulher, o corpo e o silêncio. In: Representações do consumo: estudos sobre a narrativa publicitária. Rio de Janeiro: Mauad/ PUC-Rio.

Sahlins, M. (1976). Culture and practical reason. Chicago: The University of Chicago Press. 